\title{
REDE DE NEGÓCIOS EM EMPRESAS DE TELECOMUNICAÇÕES: O CASO ALGAR TELECOM
}

\section{RESUMO}

O presente estudo volta-se para a temática de rede de negócios em empresas de telecomunicações e tem como objeto de estudo a Algar Telecom, que se destaca por ser uma das empresas mais inovadoras e rentáveis no setor de telecomunicações. Com a pesquisa buscou-se investigar a intensidade da rede de negócios formada pela Algar Telecom, objetivando o entendimento de quais fundamentos teóricos podem ser aplicáveis ao setor de telecomunicações. Foi realizada uma revisão da literatura abordando temas relacionados às empresas de telecomunicações e rede de negócios, sendo que tais dados constituíram o alicerce para o desenvolvimento da pesquisa empírica. Trata-se de uma pesquisa exploratória descritiva, qualitativa, optando-se pelo método de estudo de caso único. A análise do caso demonstrou que a rede de negócios da Algar Telecom tem baixa intensidade nas redes estudadas, sendo que seis fundamentos teóricos foram observados e apenas 2 em maior intensidade, mostrando que dada as particularidades do setor, nem todos os fundamentos podem ser aplicáveis. Este artigo contribui tanto academicamente ao ampliar o conhecimento sobre a temática quanto com a prática de empresas de telecomunicações inseridas em um ambiente volátil e altamente competitivo.

Palavras-chave: Rede de Negócios; Telecomunicações; Fundamentos Teóricos.

\section{BUSINESS NETWORK FOR TELECOMMUNICATION COMPANIES: ALGAR TELECOM CASE}

\begin{abstract}
This study turns to the topic of business networking in telecom companies and has as its object of study Algar Telecom, which stands out for being one of the most innovative and profitable companies in the telecommunications industry. Through research we sought to investigate the intensity of the business formed by Algar Telecom network, aiming to understanding witch theoretical foundations may apply to the telecommunications sector. Was done a literature review covering topics related to telecommunications and business networking companies, these data formed the foundation for conducting the empirical research. This is an exploratory-descriptive, qualitative research, using the method of single case study. The analysis of the case showed that the business network of Algar Telecom has low intensity, with six theoretical foundations observed and only 2 at a higher intensity, showing that given the particularities of the sector, not all foundations may apply. This article contributes academically to expand knowledge on the subject and with the practice of telecommunications companies entered into a volatile and highly competitive environment.
\end{abstract}

Keywords: Business Networking; Telecommunications Industry; Theoretical Foundations. 


\section{RED DE NEGOCIOS EMPRESAS DE TELECOMUNICACIONES: EL CASO ALGAR TELECOM}

\section{RESUMEN}

Este estudio se convierte en el tema de redes de negocios en empresas de telecomunicaciones y su objeto de estudio Algar Telecom, que se destaca por ser una de las empresas más innovadoras y rentables de la industria de las telecomunicaciones. Con la investigación trató de investigar la intensidad de la red comercial formada por Algar Telecom, con el objetivo de la comprensión de los fundamentos teóricos que puedan aplicarse al sector de las telecomunicaciones. Una revisión de la literatura se llevó a cabo sobre temas relacionados con las telecomunicaciones y las empresas de la red empresarial, y estos datos forman la base para el desarrollo de la investigación empírica. Se trata de una investigación cualitativa descriptiva, exploratoria, optando Es el método de estudio de caso único. El caso del análisis mostraron que el tejido empresarial de Algar Telecom tiene una baja intensidad en las redes estudiadas, y no se observaron seis fundamentos teóricos y sólo 2 a una mayor intensidad, mostrando que, dadas las particularidades del sector, se pueden aplicar no todos los fundamentos. Este artículo contribuye tanto académicamente para ampliar conocimientos sobre el tema como la práctica de las empresas de telecomunicaciones se inserta en un entorno volátil y altamente competitivo.

Palabras-clave: Red del asunto; Telecomunicaciones; Fundamentos teóricos.

Patricia Viveiros de Castro Krakauer ${ }^{1}$ Jaércio Alex Silva Barbosa ${ }^{2}$ Rita de Cácia Rodrigues de Oliveira Knop ${ }^{3}$

\footnotetext{
${ }^{1}$ Doutora em Administração pela Universidade de São Paulo - USP. Professora Convidada da Universidade de São Paulo - USP. Brasil. E-mail: pkrakauer@terra.com.br

2 Especialização em Gestão Estratégica pela University of Miami, Estados Unidos. Diretor do V A Barbosa Desenvolvimento Profissional e Gerencial. Brasil. E-mail: jaerciobarbosa@ig.com.br

${ }^{3}$ Mestre em Engenharia de Produção pela Universidade Federal de Santa Catarina -UFSC. Professora da Universidade Anhembi Morumbi - UAM. Brasil. E-mail: ritarodriguesknop@gmail.com
} 


\section{INTRODUÇÃO}

Nas últimas décadas a sociedade tem observado um incremento significativo na sua capacidade de comunicação. Além de crescer, as telecomunicações tem se popularizado nos últimos anos, favorecendo tanto a sociedade de uma forma geral quanto à economia e o crescimento das empresas inseridas no setor de tecnologia da informação e comunicação (TIC).

Dados do The World Bank Group (2012) revelam que o número de telefones celulares no mundo, ao final de 2011, ultrapassou 6 bilhões de unidades, e o número de usuários de internet já são mais de 2,5 bilhões. A incorporação da internet e do telefone celular no dia a dia das empresas e pessoas introduziu novos elementos de competitividade, permitindo a criação de inovadoras formas de relacionamento, novos serviços e diferentes maneiras de fazer negócios.

Tal expansão favorece o desenvolvimento econômico não apenas do setor telecomunicações, na medida em que os efeitos da introdução de novas tecnologias podem ser observados em diversos outros setores, como o da saúde e o da educação. Recentes pesquisas, como as de Tigre (2010) e The World Bank Group (2012), mostram que investimentos em comunicação e tecnologia estão diretamente associados aos principais benefícios econômicos como alta produtividade, baixo custo, novas oportunidades na economia, geração de empregos, inovação e crescimento de mercado.

No Brasil tal cenário não é diferente e o setor de telecomunicações também tem se mostrado estratégico para impulsionar a economia. A relevância do setor no Brasil pode ser observada em função dos investimentos feitos nos últimos 10 anos, bem como o crescimento do número de clientes e da utilização de serviços. Segundo a pesquisa da GSM Association (GSMA, 2012) a previsão para 2016 é que existam mais de 75 milhões de smartphones no país, sendo que os serviços móveis podem ser considerados como fundamentais para a transformação socioeconômica que se observa no Brasil nos últimos anos ao transformar a comunicação de indivíduos e empresas, além de favorecer a empregabilidade que é alta no setor: aproximadamente 250.000 funcionários.

Apesar de tais constatações de sucesso, a pesquisa acima mencionada alerta para as dificuldades que enfrenta o setor, com relação às restrições impostas e burocracia que dificultam o investimento e, consequentemente, a competitividade das empresas de telecomunicações. Em um ambiente de grandes transformações no mercado de TIC as empresas que participam desta indústria passam por grandes desafios, sendo que os principais estão relacionados ao ambiente altamente competitivo, com poucos e fortes players, e a existência de empresas de menor porte que vem conquistando também o seu espaço.

Tais desafios demandam novas estratégias organizacionais que permitam responder as diversas pressões competitivas. A potencialização das redes de negócios dentro do setor de telecomunicações pode ser uma das respostas estratégicas para que as empresas possam desenvolver diferenciais competitivos para enfrentar as questões colocadas. Sobre a questão do maior ganho competitivo em empresas que operaram através de redes, destaca-se a pesquisa de Ali-Yrkkö (2000) sobre a Nokia.

No Brasil a empresa Algar Telecom se destaca no setor de telecomunicações por ser uma das empresas mais inovadoras do país de acordo com o ranking Best Innovator 2013, além de ser a empresa mais sustentável do setor e estar entre as 10 empresas mais rentáveis de 2013, conforme o anuário da Telecom (ALGAR, 2014). Em função de tais premiações e a partir de conversas informais com os gestores da empresa, questionou-se sobre a constituição da Algar Telecom em uma rede de negócios, o que poderia ser o motivo de tais resultados. A partir dessa constatação buscou-se investigar a intensidade da rede de negócios formada pela Algar Telecom, objetivando o entendimento de quais fundamentos de Zaccarelli, Telles, Siqueira, Boaventura e Donaire (2008) podem ser aplicáveis ao setor de telecomunicações.

Considera-se que a análise proposta contribui tanto academicamente quanto para a prática empresarial: por um lado amplia o conhecimento sobre a temática, explorando novas possibilidades através da verificação de fundamentos já existentes. Por outro, poderá contribuir com empresas de telecomunicações inseridas em um ambiente volátil e altamente competitivo, uma vez que a constituição em redes de negócios poderá contribuir para a geração de diferenciais competitivos que venham ao encontro da dinamicidade e da necessidade de capital intensivo exigido pelo setor.

\section{FUNDAMENTAÇÃO TEÓRICA}

Considerou-se a fundamentação teórica como o alicerce para a estruturação da pesquisa de campo, pesquisando-se sobre rede de negócios, fundamentos teóricos propostos por Zacarelli et al. (2008) e empresas de telecomunicações no Brasil.

\subsection{Rede de negócios e os fundamentos de Zaccarelli et al. (2008)}

As especificidades de rede de negócios (RN) como fidelização, parceria e cooperação permitem que as empresas organizadas em rede possam atuar de forma mais competitiva nos mercados contemporâneos. Porter (1986), já na década de 80 , considerava que o 
desenvolvimento da rede de negócios em si afeta todas as empresas envolvidas na rede, o que pode modificar a competitividade da indústria. A isto Zaccarelli et al. (2008, p. 08) acrescentam que "quanto mais evoluída for uma rede de negócios maior será o seu poder competitivo".

A constatação de que a vantagem competitiva de empresas organizadas em rede é mais facilmente alcançada uma premissa básica para a constituição de uma RN, conquistada através da sinergia entre as empresas e facilitada por novas tecnológicas que possibilitam maior comunicação entre pessoas e organizações, além da abertura mercadológica (DUTRA; ZACCARELLI; SANTOS, 2008).

A participação em rede de negócios favorece também a inovação. Domazet e Saric (2009) comentam que empresas de menor porte da área de telefonia celular organizadas em redes conseguem ter uma comunicação mais inovativa, além de possuir um share mais significativo no mercado europeu, conseguir influenciar a decisão de compra do consumidor e desenvolver estratégias mais competitivas.

Rede de negócios, entendida no presente estudo pela definição de Boaventura e Siqueira (2008) como um conjunto de empresas cuja fidelização nos negócios se encontra em um grau tal que permite a identificação do agrupamento, já existiam desde a época da Companhia das Índias Ocidentais, e podem ser exemplificadas, segundo os mesmos autores citado acima, através das empresas de agribusiness existentes no mundo todo, das keiretsu japonesas ou das chaebol coreanas - LG, a Daewoo ou a Samsung. A estas,
Zaccarelli et al. (2008) acrescentam a rede da Toyota e a General Motors.

Várias são as características de redes de negócios citadas na literatura e tais definições dependem da abordagem que se adota para estudá-las. Dutra et al. (2008) apresentam um quadro conceitual a partir da análise de trabalhos de Castells (1999), Human e Provan (1997), Oliver e Ebers (1998) e Marcon e Moinet (2001), no qual determinam oito características que se destacam e convergem em todas as abordagens pesquisadas: compartilhamento de recursos, práticas informais ou regras, competências sinérgicas ou complementares, reciprocidade, aprendizagem ou evolução, poder de troca, posição ou espaço ocupado na rede e alinhamento da proposta de valor.

A fidelização surge como uma variável que se apoia na racionalidade estratégica, buscando no seu cerne compreender a competitividade a partir do entendimento de que a sinergia, a complementariedade e a entrega de valor são fundamentais para o desenvolvimento de vantagens competitivas (DUTRA et al., 2008).

A partir de tais constatações, Zaccarelli et al. (2008, p. 23) elaboraram um quadro referencial de fundamentos que "se constituem em evidências observáveis da vantagem competitiva do sistema supra empresarial", acreditando que compreender uma rede de negócios está além do entendimento de processos de fidelização. No Quadro 1 tais fundamentos, com as respectivas descrições e métricas, podem ser analisados.

\begin{tabular}{|c|c|c|}
\hline & FUNDAMENTO & DESCRIÇÃO E MÉTRICA \\
\hline 1 & Fidelização & $\begin{array}{l}\text { Proximidade entre cliente e fornecedor, podendo ser medida através do nível } \\
\text { de relacionamento existente entre as empresas. }\end{array}$ \\
\hline 2 & $\begin{array}{l}\text { Compra direta de } \\
\text { insumos }\end{array}$ & $\begin{array}{l}\text { Relação imediata entre usuários e produtores de um determinado produto, } \\
\text { sendo a métrica sugerida o número de intermediários em relação ao número } \\
\text { total de empresas. }\end{array}$ \\
\hline 3 & $\begin{array}{l}\text { Abrangência de } \\
\text { negócios }\end{array}$ & $\begin{array}{l}\text { Nível de incorporação de processos e operações de negócios, } \\
\text { compreendendo o conjunto de transformações integradas demandadas para a } \\
\text { oferta de produtos. }\end{array}$ \\
\hline 4 & $\begin{array}{l}\text { Especialização das } \\
\text { empresas }\end{array}$ & $\begin{array}{l}\text { Grau de domínio das competências em produção, desenvolvimento e } \\
\text { inovação dos produtos demandados ao longo da rede, associado à eficiência } \\
\text { e qualidades superiores. Avaliada pelo número de negócios da mesma } \\
\text { indústria ou setor. }\end{array}$ \\
\hline 5 & $\begin{array}{l}\text { Agilidade na } \\
\text { substituição de } \\
\text { empresas }\end{array}$ & $\begin{array}{l}\text { Medida da rapidez ou prontidão de movimento no afastamento de um } \\
\text { negócio deficiente e da recomposição da rede. }\end{array}$ \\
\hline 6 & Homogeneidade & $\begin{array}{l}\text { Está relacionada à intensidade de fluxos físicos e lógicos da rede, medida } \\
\text { pelo grau de variação de estoques ou de amplificação no tempo. }\end{array}$ \\
\hline 7 & $\begin{array}{l}\text { Introdução de } \\
\text { inovações }\end{array}$ & $\begin{array}{l}\text { Indica a capacidade e orientação para a introdução de inovações na rede de } \\
\text { negócios. São as competências que uma rede possui na incorporação ou } \\
\text { desenvolvimento de processos, procedimentos e práticas inovadoras } \\
\text { voltadas para o alinhamento entre os negócios ou otimização de fluxos. } \\
\text { Analisada pela idade de tecnologias adotadas por demanda externa (anos). }\end{array}$ \\
\hline
\end{tabular}


Rede de Negócios em Empresas de Telecomunicações: O Caso Algar Telecom

\begin{tabular}{|c|c|l|}
\hline $\mathbf{8}$ & Aperfeiçoamento & $\begin{array}{l}\text { Introdução de novas tecnologias: aperfeiçoamento, identificação e adoção de } \\
\text { novas tecnologias pelo agrupamento. Avaliação da idade das tecnologias em } \\
\text { uso (anos). }\end{array}$ \\
\hline $\mathbf{9}$ & Compartilhamento & $\begin{array}{l}\text { Relacionado ao compartilhamento de investimentos, riscos e lucros, sendo } \\
\text { um indicador da intensidade de colaboração e integração entre negócios de } \\
\text { uma rede, sugerindo o grau de desenvolvimento conjunto. }\end{array}$ \\
\hline $\mathbf{1 0}$ & Estratégia & $\begin{array}{l}\text { Existência efetiva e intencional de orientação integrada para ação e decisão } \\
\text { das empresas participantes do agrupamento. Adoção de estratégia em rede } \\
\text { determinada pela competição com outras redes. }\end{array}$ \\
\hline
\end{tabular}

Quadro 1 - Descrição e métricas dos fundamentos

Fonte: Baseado em Zaccarelli et al. (2008, p. 200)

Destaca-se que para se ponderar sobre os fundamentos apresentados no Quadro 1 foram considerados dois grupos, de acordo com o preconizado por Zaccarelli et al. (2008, p. 106): (1) os cinco primeiros fundamentos podem existir em redes que funcionem por auto-organização, mas com uma dinâmica ineficiente, e (2) para os últimos cinco fundamentos é fundamental a existência de governança, de forma a garantir a "continuidade efetiva do movimento evolucionário".

Pela consideração dos atuais pesquisadores trata-se de um quadro consistente com as pesquisas até então realizadas e por apresentar alternativas de métricas para a análise de redes a partir do conjunto de fundamentos propostos, o quadro conceitual apresentado no Quadro 1 foi utilizado como pilar do presente estudo.

\subsection{Telecomunicações no Brasil}

Segundo estudo do Instituto de Pesquisa Econômica Aplicada (IPEA, 2010) o setor de telecomunicações vem passando por transformações importantes nas últimas décadas. O estudo destaca a convergência entre as tecnologias envolvidas no desenvolvimento e na fabricação dos equipamentos que compõem a infraestrutura física necessária à oferta de serviços de telecomunicações e as tecnologias pertencentes a outros setores, como tecnologia da informação (TI), computação em rede e eletrônica de consumo.

Ainda segundo o mesmo estudo, uma consequência dessas mudanças é que a infraestrutura física propriamente dita deixa de ser o principal responsável pela dinâmica econômica do setor de telecomunicações, sendo substituído pelos serviços. Este fato impacta nas redes de negócios formadas em torno dos principais competidores do mercado de telecomunicações, mudando a sua importância relativa no cenário competitivo.

Outro fator que ajudou a definir a dinâmica competitiva atual do setor de telecomunicações no Brasil foi o processo de privatização do sistema iniciado em 1998. Segundo a ANATEL (2011) os efeitos da privatização foram claros e propiciaram o aumento da competitividade e da profissionalização do setor, deixando um legado positivo com a sua implementação, como pode ser observado em aspectos relacionados ao valor da linha telefônica, aos altos investimentos em infraestrutura e ao aumento da taxa de digitalização da rede.

Além destes efeitos houve outros que podem ser considerados também fundamentais para o entendimento da dinâmica do setor e essenciais no contexto do presente estudo. Com a privatização, no primeiro momento, surgiram diversas novas empresas operadoras de rede para prestação de serviços de telecomunicações. Contudo, a partir do ano de 2000, pôde ser observado um processo de consolidação do setor, com fusões e aquisições, resultando em alta concentração do mercado em alguns poucos grupos econômicos. Segundo o IPEA (2010) a privatização que deveria gerar um processo de liberalização, que visava aumentar a competição, na prática, resultou em uma nova concentração das empresas prestadoras de serviços de telecomunicações, o que modifica o poder dos agentes pertencentes às redes de negócios relacionadas com o setor de telecomunicações, aumentando a importância do Leão da Rede para a sua estruturação. Apenas destacando, leão da rede para Zaccarelli et al. (2008) seriam as empresas que possuem a posição central na rede de negócios.

Este cenário apresenta o grau de competitividade e a complexidade do setor de telecomunicações, uma vez que se trata de uma indústria com grandes empresas predominantemente estrangeiras. Empresas nacionais, com enfoque regional, como a Algar Telecom, têm sobrevivido a fusões e aquisições ofertando produtos e serviços competitivos. Tal complexidade pode ser observada no estudo de Considera, Franco, Saintive, Teixeira, Pinheiro, Moraes, Santana e Soares (2002) que alerta para aspectos relacionados a verticalidade do mercado com questões de competitividade do setor. Ao comparar o mercado brasileiro com o norte-americano, comentam que a estrutura monolítica, verticalmente integrada da indústria, não tem respaldo em teorias econômicas, sendo que, contudo, existem práticas anticompetitivas verticais nas quais a concorrência por si só não garante um sistema saudável de 
competitividade. A concorrência parece ser um dos pilares do setor, inclusive regulamentado pela ANATEL (2011) através do Plano Geral de Metas de Competição.

Especificamente sobre rede de negócios em empresas de telecomunicações vale destacar que poucos são os trabalhos que contemplam tal temática, sendo que uma visita feita na base de dados da Web of Science (2013) em Junho/2013 apresentou apenas 24 trabalhos sobre essa temática e na do Scientific Periodicals Electronic Library (SPELL, 2013) em Outubro/2013 não apresentou trabalhos que despontassem nessa direção. Analisando-se temas correlatos, identificaram-se alguns esforços, como os de Domazet e Sarić (2009), Fransman (2002a, 2002b e 2007) e Zhao e Liu (2008).

Zhao e Liu (2008) preocupam-se com a competitividade do setor e preconizam que o trabalho integrado de empresas do setor de telecomunicações é uma forma para lidar com as rápidas mudanças proporcionadas pelo desenvolvimento tecnológico que acometem o setor de telecomunicações. Analisando a indústria à luz da teoria das capacidades dinâmicas, acreditam que as empresas de telecomunicações precisam constantemente se reinventar para acompanhar a dinamicidade que lhe é imposta pelas características do mercado em que estão inseridas.

Domazet e Sarić (2009) concordam com tal ponto de vista, mas argumentam que arranjos entre empresas de telecomunicações podem favorecer a competitividade das mesmas, que passam a ter maior market share e poder de influência. A cooperação entre empresas que estrategicamente possuem alianças também favorece a entrada em novos mercados, a inovação e até a possibilidade de oferecer custos mais baixos ao cliente. Acrescentam que várias são as formas de alianças e parcerias que podem ser observadas em empresas de telecomunicação e que tal modelo de negócio está em crescimento.

Fransman (2002a, 2002b e 2007) citado no relatório do IPEA (2010), sugere um modelo em camadas, que denominou de layer model, para estudar a evolução da estrutura geral do setor de telecomunicação. Tal modelo, segundo o autor, é largamente usado como um quadro cognitivo que ajuda a perceber as relações entre os diferentes agentes do setor e será adotado no presente estudo por ser a referência na literatura que melhor descreve os diversos agentes da cadeia de telecomunicações (Quadro 2).

\begin{tabular}{|c|l|l|}
\hline CAMADA & \multicolumn{1}{|c|}{ PAPEL } & \multicolumn{1}{|c|}{ EXEMPLOS } \\
\hline VI & Consumidor Final & Pessoa Física e Jurídicas \\
\hline V & Instaladores & Engeset \\
\hline III & Canais de Venda & $\begin{array}{l}\text { Americanas.com, Banco do Brasil } \\
\text { (BB), Globo.com, Google, } \\
\text { Provedor de plataformas, } \\
\text { conteúdo e aplicações } \\
\text { Submarino, Terra, UOL, Yahoo, } \\
\text { You Tube }\end{array}$ \\
\hline II & $\begin{array}{l}\text { Operador de rede Convergente } \\
\text { Ilaro, Embratel, Net, Companhia } \\
\text { de Telecomunicações do Brasil } \\
\text { Central (CTBC), GVT, Oi, Brasil } \\
\text { Telecom, Sercomtel, Vivo, TIM }\end{array}$ \\
\hline \multirow{2}{*}{$\begin{array}{l}\text { Provedores de elementos de rede } \\
\text { (equipamentos de } \\
\text { telecomunicações, hardware e } \\
\text { software de computadores e } \\
\text { eletrônica de consumo) }\end{array}$} & $\begin{array}{l}\text { Alcatel-Lucent, Cisco, Ericsson, } \\
\text { Huawei, Motorola, Nokia- } \\
\text { Siemens }\end{array}$ \\
\hline
\end{tabular}

Quadro 2 - Estrutura do setor de telecomunicações

Fonte: Adaptado do IPEA (2010), a partir de Fransman (2002a, 2002b e 2007)

\section{MÉTODO DA PESQUISA}

Buscando-se respostas ao questionamento delineado no capítulo 1 , a presente pesquisa possui a seguinte caracterização geral, fundamentada em Gil (2002) e Marconi e Lakatos (2005): (1) com relação a sua natureza, trata-se de uma pesquisa exploratória e descritiva, em função da necessidade de descrever o caso da empresa e de explorar novas possibilidades acadêmicas, (2) possui abordagem qualitativa por ser essa uma possibilidade para estudos que possuam tal natureza e buscam entender em profundidade determinado fenômeno, (3) como método foi utilizado o estudo de caso considerado adequado pelos atuais 
pesquisadores dado o problema de pesquisa e (4) utilizará a pesquisa documental e a entrevista em profundidade como procedimentos de coleta de dados.

Com relação ao método utilizado vale destacar que foi realizado um estudo de caso único, tendo como objeto de estudo a empresa Algar Telecom, sediada em Uberlândia, Minas Gerais. Pela definição de Yin (2005, p. 28), o estudo de caso é uma pesquisa empírica que investiga um acontecimento baseado na experiência real, sendo esse método especialmente interessante quando não está definido com exatidão o limite entre o fenômeno e o contexto, o que ocorre no questionamento proposto sobre a constituição de uma rede de negócios em empresas de telecomunicações. A isto, autores como Gil (1987), Tull (1976) e Eisenhardt (1989) comentam sobre a profundidade e o detalhamento de informações que podem ser obtidas pelo estudo de caso e nem sempre possíveis com outros métodos de pesquisa.

O trabalho de Zanni, Moraes e Mariotto (2011, p. 8) ressalta as características do estudo de caso único e comenta que o seu uso é aconselhável para a "a geração de insights tanto para a teoria como para a prática em administração de empresas", buscando a especificidade dos acontecimentos. Casos únicos são também interessantes na medida em que geram significados para as organizações, possibilitando maior aprendizado do conhecimento existente. Fora isso, um dos fundamentos de Yin (2005) para a utilização de caso é a existência de um caso representativo ou típico da situação em pesquisa, de modo a aprender lições que possam divulgar achados interessantes sobre a instituição em investigação.

Para a seleção da empresa, considerou-se tanto a adequação do caso ao propósito da pesquisa quanto à facilidade de acesso aos dados e entrevistados. O caso da Algar Telecom torna-se interessante à luz metodológica em função de ser uma das poucas empresas do setor que tem procurado estimular relações de mais longo prazo com seus parceiros, promovendo maior inovação e competitividade, além de ter se destacado no setor conforme comentado do capítulo 1 do atual artigo.

Para a compreensão do caso em estudo, foram considerados tanto dados secundários, através da realização de pesquisa na homepage da empresa estudada, quanto dados primários, obtidos com entrevistas individuais em profundidade. Como instrumento para a realização das entrevistas foi elaborado um roteiro semiestruturado à luz da revisão teórica apresentada no capítulo 2, previamente testado com um executivo do setor em Setembro/2012.

Para a verificação dos fundamentos de Zaccarelli et al. (2008), apresentados no Quadro 1, foi adotada uma escala de três níveis de intensidade, onde o nível zero foi considerado para quando o fundamento não era observado, o nível um quando era verificado mas não exemplificado pelos entrevistados e o dois quando além de ser observado pelos autores do presente artigo eram também exemplificados pelos entrevistados.

A pesquisa de campo foi realizada em Outubro/2012. Foram realizadas duas entrevistas em profundidade com os gestores da empresa, com duração de aproximadamente 1 hora cada, sendo gravadas. Considerou-se as entrevistas adequadas para o estudo pelo perfil dos entrevistados (Quadro 3), ambos com 20 ou mais anos de trabalho na empresa e com funções condizentes com a problemática da pesquisa.

\begin{tabular}{|c|c|l|l|}
\hline Entrevistado & $\begin{array}{c}\text { Tempo de } \\
\text { empresa }\end{array}$ & \multicolumn{1}{|c|}{ Cargo } & \multicolumn{1}{c|}{ Função } \\
\hline 1 & 31 anos & $\begin{array}{l}\text { CTO - Chief } \\
\text { Technology } \\
\text { Officer }\end{array}$ & $\begin{array}{l}\text { Responsável por toda definição e planejamento de novas } \\
\text { tecnologias e gestão de redes, sendo responsável direta } \\
\text { pelas duas cadeias de fornecimento (tecnologia e } \\
\text { operações de campo). }\end{array}$ \\
\hline 2 & 20 anos & $\begin{array}{l}\text { Diretor de } \\
\text { Negócios } \\
\text { Corporativos }\end{array}$ & $\begin{array}{l}\text { Responsável pela área de compra e venda entre empresas } \\
\text { de Telecom, isto é, as empresas compram serviços entre } \\
\text { elas. }\end{array}$ \\
\hline
\end{tabular}

Quadro 3 - Perfil dos entrevistados

Os dados obtidos foram transcritos e analisados de forma qualitativa, procurando descrever e comparar os mesmos com a literatura, especificamente com os fundamentos apresentados no Quadro 1, constante na fundamentação teórica. As etapas realizadas foram as propostas por Yin (2005): (1) elaboração do protocolo de pesquisa, (2) busca de evidências que vão compor o caso e (3) categorização dos achados, comparando-os com a teoria.

Deve-se ressaltar que este estudo tem limitações no que se refere à generalização dos dados, uma vez que foi utilizada uma pesquisa qualitativa com estudo de caso único, não possibilitando a extrapolação dos dados para todo o setor de TIC, dada as especificidades contextuais da empresa pesquisada. Sobre isso Zanni et al. (2011) comentam não ser a generalização dos dados típica de um estudo de caso único, já que o mesmo busca a especificidade. 


\section{ANÁLISE DE RESULTADOS}

Após o levantamento dos dados secundários e primários, os achados foram analisados à luz da teoria apresentada no capítulo 2, conforme preconizado por Yin (2005).

\subsection{Apresentação da Algar Telecom}

A Algar Telecom faz parte de um grupo empresarial constituído em 1929 e com atuação em todo o território nacional. Composto por nove empresas atuantes nos setores de TI/Telecom, Agro, Serviços e Turismo, possui cerca de 22 mil funcionários e atende mais de 2 milhões de clientes.

A Algar Telecom, especificamente, possui mais de 50 anos e 800 mil clientes, detentora da marca CTBC. Fundada em 1954, em Uberlândia, pelo mineiro Alexandrino Garcia e impulsionada pelo seu filho Luis Alberto Garcia e atualmente liderada pelo neto Luiz Alexandre Garcia é reconhecida no mercado em que atua por sua diferenciação em atendimento e a forte cultura de inovação nas áreas de telefonia fixa, celular, banda larga, serviços corporativos de dados e TV por assinatura.

Tendo como seus principais concorrentes multinacionais de grande porte, tais como grupo Telefônica, grupo America Móvel, Oi e TIM, e inserida em um mercado com acirrada competição, a longevidade da Algar Telecom está pautada em sua história de inovação e um atendimento diferenciado e ágil, segundo os executivos entrevistados. O espírito inovador da Algar Telecom pode ser observado em alguns eventos tais como: primeira a implantar uma rede comercial de fibras ópticas no País, em 1984, lançamento de reconhecimento de fala e telefone público para deficientes físicos de voz e audição, lançamento do celular pré-pago em todo o Brasil, e, mais recentemente, foi a primeira empresa a oferecer tecnologia $3 \mathrm{G}$ para o interior do País.

O reconhecimento veio através do recebimento de prêmios ganhos pela empresa nos últimos anos, muitos voltados à gestão de clientes e excelência de atendimento que podem ser vistos no site da organização. Além do reconhecimento mercadológico, a Algar Telecom apresenta solidez financeira com sua abertura de capital em 2007, com faturamento bruto de
$\mathrm{R}$ \$ 2,2 bilhões e com EBTDA consolidado em $\mathrm{R} \$ 411$ milhões em 2011 (ALGAR, 2014).

Com constante preocupação com a sustentabilidade, tais aspectos já fazem parte da missão e dos valores organizacionais que alia a forma sustentável de ser com o servir e interagir pessoas e negócios, possui uma trajetória marcada pela seriedade e sucesso de suas operações com o estabelecimento de várias alianças com empresas parceiras e aquisições de outras essenciais para a competitividade do seu negócio.

\subsection{Análise da $R N$ com base nos fundamentos de Zaccarelli et al. (2008)}

A Algar Telecom se relaciona para o desenvolvimento de suas atividades principalmente com cinco grupos distintos de empresas, são elas: Instaladores/Reparadores, Fornecedores de TI, Fornecedores de Equipamentos, Canais de Venda e Outras Empresas de Telecom. O presente estudo focouse em identificar os fundamentos de quatro destes grupos: (1) os instaladores/reparadores, formada por uma empresa do grupo - a Engeset - que desenvolve o trabalho de instalação e reparo dos serviços e produtos da Algar Telecom junto aos clientes finais da empresa; (2) fornecedores de TI, formada por grandes empresas como: Oracle, IBM, SAP, Cisco, HP e pequenas e médias empresas locais; (3) fornecedores de equipamentos formados por grandes empresas como Huawei e Ericsson e também pequenas empresas que fornecem equipamentos periféricos como modens e (4) outras operadoras como Telefônica, Grupo Telemex e Oi que fornecem serviços como link de dados e compartilhamento de redes. As pequenas e médias empresas tanto fornecedoras de TI quanto de equipamentos, de maneira geral, foram desenvolvidos localmente, algumas sendo formadas por antigos funcionários da Algar Telecom.

Avaliou-se a intensidade dos fundamentos adotando uma escala de três níveis de intensidade explicada no capítulo da metodologia, sendo importante destacar que ao estabelecer os níveis de intensidade houve uma preocupação em identificar e demonstrar elementos que reforçam os fundamentos e os que enfraquecem. Os níveis foram estabelecidos através da ponderação qualitativa desses fatores e os resultados podem ser visualizados no Quadro 4. 
Rede de Negócios em Empresas de Telecomunicações: O Caso Algar Telecom

\begin{tabular}{|c|c|c|c|}
\hline & FUNDAMENTO & $\begin{array}{c}\text { INTENSIDADE } \\
(0-1-2)\end{array}$ & FONTE \\
\hline 01 & $\begin{array}{l}\text { Fidelização } \\
\text { - Instaladores/Reparadores } \\
\text { - Grandes Empresas Fornecedoras de TI } \\
\text { - Pequena/Média Empresas Fornecedoras de TI } \\
\text { - Grandes Empresas Fornecedores de Equipamentos } \\
\text { - Pequena/Média Empresas Fornecedoras de } \\
\text { Equipamentos } \\
\text { - Outras Empresas de Telecom }\end{array}$ & $\begin{array}{l}1 \\
0 \\
1 \\
0 \\
1 \\
0\end{array}$ & $\begin{array}{l}\text { Primária e } \\
\text { Secundária }\end{array}$ \\
\hline 02 & Compra direta de insumos & 2 & $\begin{array}{l}\text { Primária e } \\
\text { Secundária }\end{array}$ \\
\hline 03 & Abrangência de negócios & 0 & $\begin{array}{l}\text { Primária e } \\
\text { Secundária }\end{array}$ \\
\hline 04 & Especialização das empresas & 1 & $\begin{array}{l}\text { Primária e } \\
\text { Secundária }\end{array}$ \\
\hline 05 & Agilidade na substituição de empresas & 1 & Primária \\
\hline 06 & Homogeneidade & 2 & $\begin{array}{l}\text { Primária e } \\
\text { Secundária }\end{array}$ \\
\hline 07 & Introdução de inovações & 1 & $\begin{array}{l}\text { Primária e } \\
\text { Secundária }\end{array}$ \\
\hline 08 & Aperfeiçoamento & 0 & $\begin{array}{l}\text { Primária e } \\
\text { Secundária }\end{array}$ \\
\hline 09 & Compartilhamento & 0 & $\begin{array}{l}\text { Primária e } \\
\text { Secundária }\end{array}$ \\
\hline 10 & Estratégia & 0 & Primária \\
\hline
\end{tabular}

Quadro 4 - Síntese dos resultados

A partir do Quadro 4 é possível observar que as relações com os diferentes grupos de empresas observadas na Algar Telecom apresentam poucas evidências de constituição de rede de negócios quando analisados sobre o prisma dos fundamentos de Zaccarelli et al. (2008). A seguir são aprofundadas estas relações e apresenta-se qualitativamente o que foi observado em relação à presença ou ausência de evidências para cada fundamento.

\section{F1: Fidelização progressiva entre fornecedores e clientes}

Mesmo focando apenas na rede de fornecedores da Algar Telecom foi possível observar comportamentos diferenciados em relação à fidelização dos vários tipos de fornecedores. Para produtos mais padronizados fornecidos por grandes empresas a fidelidade é próxima de zero, para produtos mais complexos, existe uma maior relação de parceria e relação de médio e longo prazo e para pequenos fornecedores locais existe uma maior proximidade e confiança.

A Algar Telecom criou há poucos anos uma Diretoria de Compras que centraliza o processo de compras com os fornecedores, o que, segundo os entrevistados, distancia os fornecedores das áreas de operação, dificultando a criação de relacionamentos baseados em outros atributos que não custo e prazo. Desta forma para produtos mais comoditizados, supridos por grandes fornecedores de TI, equipamentos ou serviços de Telecom, não foi observado nenhum relacionamento notadamente diferenciado com a Algar. Esta, ao comprar seus produtos ou serviços, faz um pedido aberto para o mercado especificando as suas necessidades através de um edital chamado de RFP (Request for proposal). Qualquer fornecedor que atender as exigências do edital de prazos e qualidade pode participar da concorrência, que é ganha, de forma geral, pelo preço mais baixo.

Um dos executivos entrevistados enfatizou a pouca cultura de parceria no setor e narrou uma situação ocorrida em 2005 em que a Algar Telecom passava por uma crise financeira e procurou seus parceiros de mais de 50 anos como Ericsson e Siemens para negociar a introdução de novas tecnologias a preços mais acessíveis. Na época, essas empresas não aceitaram essa negociação, levando a Algar Telecom a ser a primeira empresa brasileira a adotar tecnologias chinesas em seu core de rede, isto é, seus principais equipamentos de rede tais como centrais telefônicas IP, gerência de redes, entre outros. Esta opção por fornecedores que não possuíam nenhuma relação anterior com a Algar Telecom em uma questão tão estratégica da empresa demonstra a fragilidade das relações entre a empresa e seus fornecedores.

Em relação ao fornecimento de serviços de telecomunicações por outras prestadoras de serviços existe uma troca constante de produtos e serviços, ou 
seja, as empresas são ao mesmo tempo clientes e fornecedoras uma das outras, o que mostra uma interdependência entre as empresas deste grupo. Os preços neste caso são ainda mais padronizados, pois, em sua maioria são determinados pela agência reguladora Anatel, tendo como principais desafios nesse caso o cumprimento entre as partes dos seus respectivos SLA, isto é, service level agreement, de instalação e reparo. Desta forma para este grupo de empresas a fidelização é próxima de zero.

Contudo, no setor de telecomunicações há produtos e projetos que por sua complexidade ou singularidade demandam o desenvolvimento de parcerias de longo prazo, projetos de infraestrutura de redes e sistemas, por exemplo, em que é necessário estabelecer uma relação de mais de 10 anos entre fornecedor e cliente. Um projeto deste tipo foi exemplificado por um dos entrevistados - chamado de "E Você". Neste projeto foi desenvolvida uma parceira de longo prazo entre a Algar, Haway e Ericsson que culminou na reestruturação da rede IP (Internet Protocol) da empresa, formando as redes conhecidas como de última geração. Neste tipo de relação pode-se observar o nível alto de fidelização, conforme as métricas propostas por Zaccarelli et al. (2008), onde é constatado que os contratos são de mais longo prazo com algumas restrições de trabalhar com outros parceiros.

Também foi observada uma relação maior de fidelidade quando analisados os fornecedores locais tanto de TI quanto de equipamentos, principalmente porque a Algar representa uma parte substancial das vendas destes fornecedores, isto é, em torno de 70 a $80 \%$. Outro motivo para maior fidelidade é que a Algar desenvolveu estes fornecedores localmente com objetivo de suprir necessidades especifica da empresa de qualidade e tempo, procurando manter relações de mais longo prazo. Contudo, mesmo com uma fidelidade maior, para a maioria dos serviços ou produtos não existe exclusividade no relacionamento.

Outro grupo analisado foi o dos instaladores/reparadores, formado por uma empresa do grupo, a Engeset. Neste caso o fato de ser uma empresa do grupo se estabelece uma relação de maior longo prazo e com maior fidelidade. Neste tipo de relação pode-se constatar que os contratos são de longo prazo com algumas restrições de trabalhar com outros parceiros. Contudo, é importante destacar que a Engeset não possui exclusividade de fornecimento em relação à Algar Telecom, sendo também fornecedora de outras empresas concorrentes.

Desta forma observou-se que a natureza das relações com os diferentes grupos é mais transacional do que de parceria, conforme define o modelo, demonstrando que o relacionamento entre a Algar Telecom e os quatro grupos analisados atendem de forma mais recorrente aos interesses de curto e médio prazo.

\section{F2: Compra direta de insumos}

Para a análise deste fundamento foi observado se os produtos ou serviços são comprados diretamente do prestador primário dos serviços ou produtos, ou se existem intermediários.

A criação de uma área que centraliza todas as compras da empresa, conforme já citado na análise do fundamento anterior, foi uma tentativa de otimizar os processos de compras. Esta área busca e estimula os fornecedores, considerados mais adequados para prover os recursos procurados, a participarem dos editais de concorrência. Desta forma a tendência é que a Algar Telecom tenha acesso a produtos sem intermediários. Para reforçar ainda mais o fundamento algumas compras de maior complexidade ficam ao encargo das áreas mais impactadas que sempre procuram o prestador primário do produto ou serviço.

É importante destacar que no caso do segmento de compra e venda atacadista entre as empresas de Telecom, o relacionamento é direto, sem intermediários. Contudo, foi observado também que nem sempre a compra direta é a ação que mais gera valor para a empresa. Compras de produtos mais rotineiros, por exemplo, foram terceirizadas para a IBM que funciona como um parceiro, neste caso.

Alguns grandes fornecedores, com objetivo de melhorar a relação com a Algar Telecom, terceirizaram os seus serviços através de representantes que pelo foco e especialização podem gerar mais valor na relação comercial. Um exemplo é a empresa CISCO que utiliza a PROMON como intermediária no desenvolvimento de sistemas e venda de equipamentos/soluções para a empresa.

Desta forma pode-se afirmar que o fundamento foi observado com maior intensidade, pois a Algar Telecom utiliza como regra a compra direta de produtos ou serviços do fornecedor primário, havendo, no entanto, algumas exceções.

\section{F3: Abrangência de negócios na rede}

Este fundamento expresso pelo alinhamento entre os vários participantes da rede que, segundo Zaccarelli et al. (2008), culminam numa redução de custo agregado com a combinação ótima de fornecimento, tecnologia e confiabilidade no interior da rede. Este fundamento foi observado de forma marginal pelos entrevistados.

Para exemplificar o ponto acima observamos que $o$ desenvolvimento das tecnologias mais importantes, tanto relacionadas à tecnologia de informação quanto aos equipamentos, como também a produção destes equipamentos está fora da influência direta da Algar Telecom. Estas tecnologias e a produção são desenvolvidas em escalas mundiais para atendimento de todo o setor com poucas adaptações à realidade específica da Algar Telecom.

Desta forma ficou pouco evidenciado para estes grupos de empresas alinhamentos que possam gerar a melhora nos custos de transação como preconizado no modelo. 


\section{F4: Especialização das empresas}

De acordo com o referencial teórico adotado nesta pesquisa (ZACCARELLI et al., 2008), a especialização compreende o nível de domínio das competências em produção, desenvolvimento e inovação dos produtos demandados ao longo da rede, associado à eficiência e qualidade superiores que são apresentadas pelos negócios que compõem a RN. Ou seja, este fundamento pressupõe a existência de um conjunto integrado de empresas dotadas de competências especializadas em determinadas atividades, operações e/ou produtos, capazes de individual ou conjuntamente apresentarem eficiência elevada e oferecem soluções eficazes voltadas ao atendimento das demandas de mercado. Assim, um maior número de fornecedores e clientes por setor pode indicar que essas empresas possuem competências mais especializadas. Os mesmos autores sugerem como métrica para avaliar este fundamento o número máximo de negócios presentes em uma empresa passível de terceirização.

Os entrevistados enxergam o processo de terceirização, tanto na Algar Telecom, quanto nas outras empresas da rede, com um processo cíclico - em 1990 a Algar Telecom foi pioneira em terceirizar a operação de campo para a Engeset, que é empresa da holding Algar focada em operações de campo, o que permitiu o foco apenas nas atividades consideradas core da empresa - planejamento e engenharia. Contudo, recentemente houve um ciclo de insourcing com reincorporação de várias atividades terceirizadas que são consideradas estratégicas: a criação da Academia Técnica responsável pelo treinamento das operações de campo é um exemplo, uma vez que a Algar Telecom entende que seu diferencial competitivo é o relacionamento próximo com seu cliente, atendendo suas principais expectativas, que é prazo e atendimento especializado. Contudo, de forma geral os entrevistados acreditam que existe um nível bom de especialização, mas que ainda existem oportunidades de terceirização de processos importantes do negócio, tanto na Algar Telecom como em outras empresas da rede, o que teoricamente poderia melhorar a competitividade da organização.

É importante destacar que este foi um fundamento muito questionado por um dos entrevistados. A dúvida é se no setor de telecomunicações a terceirização gera maior competitividade. Foi dado o exemplo de duas empresas indianas, que estão entre as mais eficientes do mundo, a Bharti Telecom que tem na terceirização o seu diferencial competitivo e a Aircel que tem no um serviço completo, com o mínimo de terceirização, uma das razões para o seu sucesso.

Desta forma pode-se afirmar que o fundamento foi observado, mas não foi possível afirmar que existe em um nível mais intenso.

\section{F5: Agilidade na substituição de empresas}

Segundo o referencial teórico adotado quanto maior a rapidez no afastamento de negócios ineficientes maior é a intensidade deste fundamento. De forma semelhante ao que ocorreu no fundamento 1 , foi observado o processo de substituição em dois níveis de fornecedores, de produtos comoditizados e de produtos de maior complexidade. Para os primeiros produtos a substituição pode acontecer a cada um ou dois anos com o lançamento de novo edital. Em relação ao fornecimento de produtos de alta complexidade e altos custos como redes, por exemplo, o fornecimento tem que ser baseado num relacionamento de pelo menos 10 anos. Neste tipo de relação os custos de troca dificilmente são menores que os custos de manutenção e por isso a substituição é muito lenta.

No caso de fornecimento no varejo existente entre as empresas de Telecom os entrevistados dividiram o processo de substituição em dois grupos: onde há alta concorrência, como em grandes centros como São Paulo, Rio de Janeiro, Belo Horizonte, onde a substituição é rápida. Já para as cidades em que não há concorrência a empresa fica refém dos grandes fornecedores.

Desta forma pode-se afirmar que o fundamento foi observado, mas é difícil ponderar o peso e o impacto dos fornecedores de produtos comoditizados em que foi observada alta substituição versos os fornecedores de produtos de maior complexidade. Por isso avaliou-se este fundamento como em nível 1.

\section{F6: Homogeneidade da intensidade de fluxos}

A premissa adotada neste fundamento é de que quanto maior é o giro dos estoques, menor são os estoques médios os custos de estocagem das empresas que participam da rede de negócios. Por consequência, mais eficiente e homogêneo é a intensidade dos fluxos.

Não existe cultura na indústria de telecomunicações dos fornecedores manterem grandes estoques, por isso a previsão de vendas tem que ser a mais próxima da realidade possível. A Algar Telecom tem como política manter estoques mínimos de segurança equivalentes a dois ou três meses de demanda dos principais componentes dos produtos/serviços vendidos. Por isso considera-se que existe o fundamento e ele foi observado com maior intensidade.

\section{F7: Introdução de inovações para alinhamento de negócios}

O modelo teórico de Zaccarelli et al. (2008) afirma que este fundamento é uma indicação da capacidade e orientação para introdução de inovações na rede de negócios. Isso se daria pelo estímulo ao compartilhamento de sugestões sobre o processo produtivo que resulte em melhorias nas operações, contribuindo assim para a diminuição no tempo e/ou do custo do produto, e aumento da eficiência. Este tipo de 
integração condiciona-se a presença de alguma governança na rede.

Não foi observada na rede analisada uma governança destacada, o que diminui a intensidade do fundamento. Os entrevistados acreditam que ainda é muito incipiente este ponto na organização. Contudo, foi constatado que quando existe a implantação de uma nova tecnologia nos processos da Algar Telecom que influenciem diretamente parceiros e fornecedores existem treinamentos ofertados pela Algar Telecom, de forma parecida os fornecedores treinam a Algar Telecom caso exista novas tecnologias desenvolvidas. O "Incademia" é o nome de um projeto que foi implantado para capacitar os parceiros no esforço conjunto de melhorarem sua operação. Todavia são eventos pontuais, não estimulados ou coordenados pela rede.

Desta forma acredita-se que este fundamento tem pouca intensidade na rede de negócios da Algar Telecom.

\section{F8: Aperfeiçoamento por introdução de novas tecnologias}

Este fundamento procura avaliar o processo de identificação e desenvolvimento de novas tecnologias pela rede. Este fundamento exige ainda maior governança que o anterior.

Este foi um fundamento observado de forma pequena na rede de negócios da Algar Telecom. As razões parecem ser de duas naturezas: a primeira está relacionada com o foco em serviços dados pela Algar Telecom para o seu negócio, o que diminui sensivelmente a pressão para introdução de novas tecnologias, e a segunda refere-se à complexidade de geração de novas tecnologias para o mercado de telecomunicações que está reservado a grandes competidores mundiais.

Desta forma verifica-se que este fundamento tem muito pouca intensidade na rede de negócios da Algar Telecom.

\section{F9: Compartilhamento de investimentos, riscos e lucros}

Este fundamento é um indicador da intensidade de colaboração e integração entre negócios de uma rede, que sugere o grau de desenvolvimento conjunto, credibilidade e postura de parceria entre empresas (ZACCARELLI et al., 2008).

Foram apontados pelos entrevistados projetos pontuais em que houve o compartilhamento de investimentos, riscos e lucros. Um exemplo foi $\mathrm{o}$ projeto Minas desenvolvido em conjunto com a Ericsson, outro exemplo são o projetos desenvolvidos em nível nacional entre prestadoras de Telecom em que é necessário complementariedade de redes e serviços como o Teletom e o Big Brother. Contudo, como os entrevistados enfatizaram, são iniciativas muito esporádicas, apontando para uma intensidade próxima de zero neste atributo.

\section{F10: Estratégia para competir como rede}

Conforme mencionado no referencial teórico desta pesquisa (ZACCARELLI et al., 2008) este fundamento evidencia a existência efetiva e intencional de orientação integrada para a formulação estratégica e de ações entre clientes e fornecedores.

Não foi observada na rede da Algar Telecom uma estratégia para competir em rede. Os entrevistados avaliam que existem alguns elementos na cultura da Algar Telecom que comparativamente aos outros grandes concorrentes do setor impactam positivamente no desenvolvimento de relacionamentos mais duradouros. "Acreditamos que parceiros insatisfeitos ou quase mortos não oferecem um bom serviço e que a pressão demasiada em elementos da cadeia prejudica a cadeia inteira", ressalta o entrevistado 1. Eles também acreditam que o desenvolvimento de relações com maior fidelidade pode e deve ocorrer na Algar Telecom de forma crescente, acompanhando a gradual maturidade do setor de telecomunicações no Brasil.

\section{CONSIDERAÇÕES FINAIS}

Esta pesquisa analisou a intensidade da rede de negócios da Algar Telecom à luz dos dez fundamentos explicitados por Zaccarelli et al. (2008). A partir da análise de dados primários e secundários pode-se observar que a RN constituída pela Algar Telecom possui baixa intensidade, apesar de ser observado na cultura da Algar Telecom uma preocupação no desenvolvimento de relacionamentos mais duradouros com os diversos agentes da RN. A intensidade fraca na RN da Algar Telecom mostra uma natureza predominantemente transacional, com pouca fidelidade ou planejamento de mais longo prazo nas relações estudadas.

Os motivos para a fraca intensidade das relações podem ser encontrados na baixa maturidade do setor de telecomunicações no Brasil que de forma competitiva e aberta existe a menos de 20 anos no país; no baixo investimento em desenvolvimento de novos produtos o que gera uma competição focada em preços e baixa diferenciação; o tamanho dos fornecedores no setor, formado em grande parte por grandes empresas multinacionais que possuem poucos incentivos em estabelecer relações mais intensas com poucas empresas do mercado e finalmente o posicionamento das empresas de Telecom em serviços o que gera peculiaridades ainda pouco estudadas na literatura sobre rede de negócios.

Sobre essa questão e atendendo aos objetivos da pesquisa, observou-se que nem todos os fundamentos são aplicáveis ao setor de telecomunicações, em função das particularidades do mesmo. Por ser um setor de desenvolvimento razoavelmente recente e pouco 
Rede de Negócios em Empresas de Telecomunicações: O Caso Algar Telecom

estável, estima-se que novos estudos serão delineados de forma a entender possibilidades da estruturação de redes de negócios em empresas telecom.

A atual pesquisa possui algumas limitações metodológicas, principalmente no que se refere a escolha do próprio método em si e a possibilidade de entrevistar somente dois executivos da empresa. Apesar de serem dois dos cinco principais executivos da Algar Telecom, acredita-se que a ampliação das entrevistas para outros executivos e outras empresas relacionadas à rede poderia ter enriquecido a pesquisa $\mathrm{e}$ ajudaria a apresentar novas evidencias sobre o assunto. Ressalta-se também que o próprio método tem suas limitações no que diz respeito à generalização, apesar de ter-se buscado a especificidade com a descrição do caso.

Sugerem-se novos estudos futuros como o entendimento da diferença do impacto de redes de negócios em diferentes setores; a influência do tamanho do fornecedor e das características do produto na formação de rede de negócios, além da relação da maturidade do setor no desenvolvimento de relações de maior intensidade nas redes desenvolvidas.

\section{REFERÊNCIAS}

ALGAR TELECOM (2014). Disponível em: http://www.algartelecom.com.br Acesso em: 29/03/2014.

Ali-Yrkkö, J. (2000). Nokia's network - gaining competitiveness from co-operation. Helsinki, ETLA, Elinkeinoelämän Tutkimuslaitos, The Research Institute of the Finnish Economy. Disponível em: http://www.etla.fi/wpcontent/uploads/2012/09/B174.pdf Acesso em: 29/03/2014.

ANATEL. (2011). Plano Geral de Metas de Competição. Disponível em: http://www.anatel.gov.br/Portal/exibirPortalNoticia s.do? acao $=$ carregaNoticia\&codigo $=23195$ Acesso em: 14/10/2012.

Boaventura, J. M. G. \& Siqueira, J. P. L. (2008). A estratégia e as redes de negócio. Anais de: $\mathrm{X}$ SEMEAD, São Paulo, FEA, USP.

Considera, C. M., Franco, F. A. L., Saintive, M. B., Teixeira, C. P., Pinheiro, M. C., Moraes, R. K., Santana, P. M. \& Soares, D. P. (2002). O Modelo Brasileiro de Telecomunicações: Aspectos Concorrenciais e Regulatórios. Disponível em: www.seae.fazenda.gov.br/central_documentos/...1/ doctrab18.pdf

Acesso em 14/10/2012
Domazet, A. \& Sarić, N. (2009). Strategies of mobile virtual network operators in the southeast Europe region. Interdisciplinary Management Research. V $5: 123-135$.

Dutra, I. S., Zaccarelli, S. B. \& Santos, S. A. (2008). As redes empresariais de negócios e o seu poder competitivo: racionalidade lógica ou estratégica? Revista de Negócios, Blumenau, v. 13, n. 1, p.11 27.

Eisenhardt, K. M. (1989). Building Theories from Case Study Research. Academy of Management Review, v. 14 , n. 4 , p. 532-550.

Fransman, M. (2002a). Mapping the evolving telecoms industry: the uses and shortcomings of the layer model. Telecommunications Policy, v. 26, n. 9-10, p. 473-483.

(2002b). Telecoms in the Internet Age: from boom to bust to...? Oxford: OxfordUniversity Press. Kokoro.

(2007). New ICT ecosystem. Edinburgh:

Gil, A. C. (2002). Como elaborar projetos de pesquisa. 4. ed. São Paulo: Atlas.

(1987). Métodos e técnicas de pesquisa social. São Paulo: Atlas.

GSMA. Brazil Mobile Observatory 2012. Disponível em: http://www.gsma.com/MO.

http://www.gsma.com/publicpolicy/wpcontent/uploads/2012/03/gsma_brazil_obs_web3 0 9_12.pdf Acesso em 12/10/2012

IPEA. (2010). Séries Eixo do Desenvolvimento Brasileiro, N. 57. Disponível em: http://www.ipea.gov.br/portal/index.php?option=co m_content $\&$ view $=$ article \&id $=1378$

Acesso em: Outubro/2012

Marconi, M. A. \& Lakatos, E. M. (2005). Fundamentos da metodologia científica. 6. ed. São Paulo: Atlas.

Porter, M. E. (1986). Estratégia competitiva: técnicas para análise de indústrias e da concorrência. Rio de Janeiro: Campus.

Spell. 2013. Disponível em: http://www.spell.org.br/ Acesso em: Outubro/2013

THE WORLD BANK GROUP. (2012). Information and Communication Technologies Department. Disponível em: www.worldbank.org/ict Acesso em $11 / 10 / 2012$ 
Tigre, P. (2010). Perspectivas do investimento em tecnologias de informação e comunicação. Relatório integrante da pesquisa Perspectivas do Investimento no Brasil. Disponível em: http://www.bndes.gov.br/SiteBNDES/export/sites/d efault/bndes_pt/Galerias/Arquivos/empresa/pesquis a/pib/pib tics.pdf Acesso em 11/12/2012.

Tull, D. S. (1976). Marketing Research: Meaning, Measurement, and Method. NY: Macmillan.

WEB OF SCIENCE. Disponível em: http://apps.isiknowledge.com/WOS_GeneralSearch input.do?product $=$ WOS\&search mode $=$ GeneralSe arch\&SID=3AiJoM85GjA5akh6mPp\&preferencesS aved Acesso em Junho/2013
Yin, R. (2005). Estudo de Caso: Planejamento e Métodos. Porto Alegre: Bookman.

Zaccarelli, S. B., Telles, R., Siqueira, J. P. L., Boaventura, J. M. G. \& Donaire, D. (2008). Clusters e Redes de Negócios: uma nova visão para a gestão dos negócios. São Paulo: Atlas.

Zanni, P. P., Moraes, G. H. S. M. \& Mariotto, F. L. (2011). Para que servem os Estudos de Caso Único? Associação Nacional de pós-graduação e pesquisa em administração, ANPAD, Rio de Janeiro. Anais de...

Zhao, Y. \& Liu, Y. (2008). Organizational change: A case study on Anhui Telecom Company. International Seminar on Business and Information Management. ISBIM, V. 2, China. 